Research Article

\title{
Chemical and Enzymatic Hydrolysis of Polyurethane/Polylactide Blends
}

\author{
Joanna Brzeska, ${ }^{1}$ Aleksandra Heimowska, ${ }^{1}$ Wanda Sikorska, ${ }^{2}$ Lidia Jasińska-Walc, ${ }^{3}$ \\ Marek Kowalczuk, ${ }^{2}$ and Maria Rutkowska ${ }^{1}$ \\ ${ }^{1}$ Department of Chemistry and Commodity Industrial Science, Gdynia Maritime University, 83 Morska Street, 81-225 Gdynia, Poland \\ ${ }^{2}$ Centre of Polymer and Carbon Materials, Polish Academy of Sciences, 34 Sklodowska-Curie Street, 41-819 Zabrze, Poland \\ ${ }^{3}$ Department of Polymer Technology, Gdańsk University of Technology, 11/12 Narutowicza Street, 80-952 Gdańsk, Poland
}

Correspondence should be addressed to Joanna Brzeska; j.brzeska@wpit.am.gdynia.pl

Received 17 February 2015; Revised 28 April 2015; Accepted 11 May 2015

Academic Editor: Yakai Feng

Copyright (C) 2015 Joanna Brzeska et al. This is an open access article distributed under the Creative Commons Attribution License, which permits unrestricted use, distribution, and reproduction in any medium, provided the original work is properly cited.

\begin{abstract}
Polyether-esterurethanes containing synthetic poly[(R,S)-3-hydroxybutyrate] (R,S-PHB) and polyoxytetramethylenediol in soft segments and polyesterurethanes with poly( $\varepsilon$-caprolactone) and poly[(R,S)-3-hydroxybutyrate] were blended with poly([D,L]lactide) (PLA). The products were tested in terms of their oil and water absorption. Oil sorption tests of polyether-esterurethane revealed their higher response in comparison to polyesterurethanes. Blending of polyether-esterurethanes with PLA caused the increase of oil sorption. The highest water sorption was observed for blends of polyether-esterurethane, obtained with $10 \%$ of R,SPHB in soft segments. The samples mass of polyurethanes and their blends were almost not changed after incubation in phosphate buffer and trypsin and lipase solutions. Nevertheless the molecular weight of polymers was significantly reduced after degradation. It was especially visible in case of incubation of samples in phosphate buffer what suggested the chemical hydrolysis of polymer chains. The changes of surface of polyurethanes and their blends, after incubation in both enzymatic solutions, indicated on enzymatic degradation, which had been started despite the lack of mass lost. Polyurethanes and their blends, contained more R,S-PHB in soft segments, were degraded faster.
\end{abstract}

\section{Introduction}

Every material immersed in living organism is affected by surrounded environment. Water is the main component of body fluids so the crucial degradation mechanism of majority implanted polymers is the chemical hydrolysis. But in fact total degradation of implant is the result of many parameters: influencing of biologic and inorganic compounds (such as enzymes, lipids, blood cells, proteins, phosphates, etc.), oxidase species (like free radicals, superoxide, hydrogen peroxide, hypochlorous acid, peroxynitrite anion, etc.) and physical-mechanical factors (fluid friction, tensions, temperature, $\mathrm{pH}$, etc.). All these factors are part of living organism strategy to attack and eliminate the foreign bodies.

Lipids are one of very important factors acting on the implanted material. They can accelerate the calcification process of polymer surface and its environmental stress cracking. Moreover lipids, when diffused between chains, can act as plasticizers of polymeric material what facilitates chains moving from polymer network. Taking under consideration that albumin is a peptide, which can be absorbed on polymer surface to form the natural junction with environment of living body, and knowing that this peptide exists in organism as lipid-complex, the higher oil sorption by investigated polymers should improve their hemocompatibility [1]. The influence of natural lipids on investigated polyurethanes can be estimated using sunflower oil.

Enzymatic degradation of implanted polymers is carried on gradually and due to the large size of the enzyme molecules begins on the sample surface. In the case of an ideal surface erosion process, a positive mass loss and no molecular weight decrease of the remaining polymers are observed. Bulk degradation occurs when water molecules penetrate into polymer network, causing the hydrolysis of chains. Random hydrolytic chain scission would take place and produce an overall reduction in molecular weight. But 
the mass loss begins when a low molecular weight fraction of the degradation products can dissolve in degradation medium.

Susceptibility to enzymatic degradation of polyurethanes and their blends was tested by incubation in a solution of porcine pancreatic lipase and porcine pancreatic trypsin. Trypsin is the proteolytic enzyme which degrades the peptide bonds whereas the ester cleavages are hydrolyzed by lipase [2]. It was reported that only pseudomonas lipase degrades PCL but Peng and his coworkers [3] stated that porcine pancreatic lipase could effectively catalyze the degradations of PCL copolymers while showing no obvious effect on its homopolymer.

Polyurethanes (PURs) are used in medicine as longterm implant materials for many years and are indispensable as veins, heart valves, and so forth $[1,4]$. Polyurethanes susceptible to degradation processes are also useful in controlled release of drugs and as the matrix for tissue repair [5-7]. Hydrolysis of chains of polyurethane includes firstly the chemical dissolution of ester and amide bonds, next, the reduction of molecular weight, and finally leaching of low molecular weight products of polymer degradation connected with the sample mass reduction [8].

The degradability of polyurethanes with different degradation rates can be achieved by using appropriate soft segments or by their blending with other polymers.

PURs contained synthetic poly [(R,S)-3-hydroxybutyrate] (R,S-PHB) and polyoxytetramethylenediol (PTMG) or poly$\varepsilon$-caprolactone (PCL) in soft segments were blended with poly $([\mathrm{D}, \mathrm{L}]$-lactide) (PLA).

$\mathrm{R}, \mathrm{S}-\mathrm{PHB}$ is the synthetic analog of natural PHB which degrades in vivo to 3-hydroxybutyric acid, a common metabolite in human blood [9]. Natural PHB is highly crystalline polymer [10] what makes it hard to process and a slow degradable material therefore replacing it by $\mathrm{R}, \mathrm{S}-\mathrm{PHB}$ with the very low crystallinity is preferable. Oligomerols of $\mathrm{R}, \mathrm{S}-\mathrm{PHB}$ are known as biocompatible and nontoxic [11]. PCL and PLA are the biocompatible polyesters that are degraded in natural environment to nontoxic products [12]. The rate of PCL degradation is very low. Term of its degradation extended even up to 3-4 years [13]. Amorphous poly([D,L]lactide) degrades much faster than PCL.

The previous investigations of the polyurethanes based on R,S-PHB and PTMG or PCL in soft segments indicated that they could be biocompatible and biodegradable in vitro [14]. Blending of polyurethanes with PLA (see Figures 1 and 2) ought to affect their degradation. The degradation process of polyurethanes (based on R,S-PHB) and their blends with PLA was conducted in phosphate buffer and enzymes solutions. The degradability of polymers was estimated by changes of their samples mass, molecular weights, and morphology of the surface. Water and oil sorption of PURs and their blends were also investigated.

\section{Experiment}

2.1. Materials. Synthesis of polyurethanes was carried out in a two-step reaction, with molar ratio of $\mathrm{NCO}: \mathrm{OH}=2: 1$ in

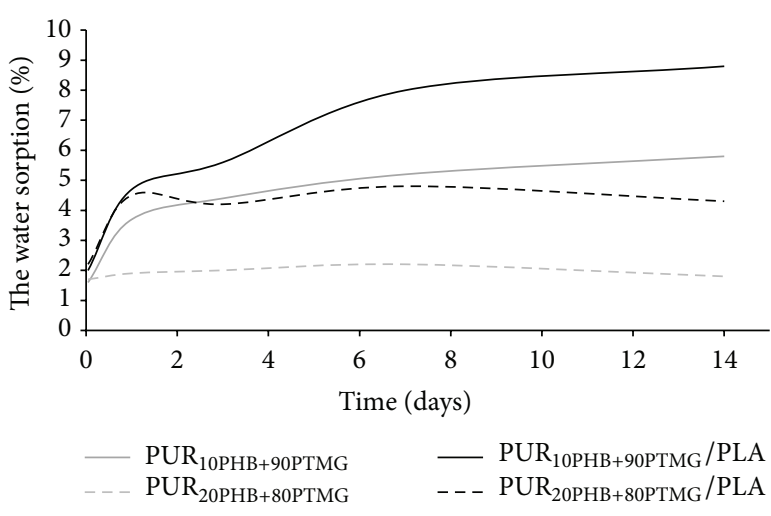

FIGURE 1: Changes of water sorption by polyether-esterurethanes and their blends with PLA during incubation in deionized water $( \pm \mathrm{SD}$ in range $0.0-1.2$ ).

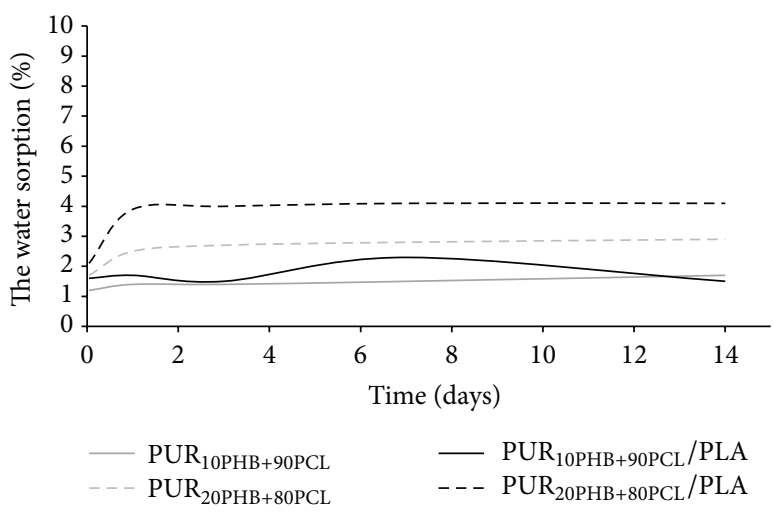

FIGURE 2: Changes of water sorption by polyesterurethanes and their blends with PLA during incubation in deionized water $( \pm$ SD in range $0.0-1.1$ ).

prepolymer step, according to procedure described earlier [15]. The hard segments of obtained new polyurethanes were synthesized with aliphatic $4.4^{\prime}$-methylene dicyclohexyl diisocyanate $\left(\mathrm{H}_{12} \mathrm{MDI}\right.$, Aldrich) and 1.4-butanediol (1.4-BD, Aldrich). The soft segments were built of PTMG $\left(M_{n} 2000\right.$, Aldrich) or PCL $\left(M_{n} 1900\right.$, Aldrich) and synthetic R,SPHB $\left(M_{n}\right.$ 1700) in weight ratio of $90: 10$ or $80: 20$. R,S$\mathrm{PHB}$ was obtained by anionic ring opening polymerization of $(\mathrm{R}, \mathrm{S})$ - $\beta$-butyrolactone initiated by 3 -hydroxybutyric acid sodium salt/18-crown-6 complex at room temperature and terminated with 2-bromoethanol [16].

Prepolymer of polyurethanes, obtained with mixed oligomerols and $\mathrm{H}_{12} \mathrm{MDI}$, was dissolved in $\mathrm{N}, \mathrm{N}^{\prime}$ dimethylformamide (DMF) and next the chains were prolonged using 1.4-BD. Formed polyurethane foils were dissolved again in DMF and next blended with PLA ( $M_{w}$ 18,000 28,000, Aldrich). The obtained blends were seasoned for two weeks at room temperature after the solvent evaporation.

2.2. Methods. The oil sorption of obtained polyurethanes was estimated by immersing of polymer samples in sunflower oil 
at $37^{\circ} \mathrm{C}$ for 24 hours and next their weighting after cleaning with filter paper [17]. For water sorption measurement the samples were immersed in deionized water for 14 days at $37^{\circ} \mathrm{C}$. Next the swollen samples were gently blotted with filter paper and weighted. Both the oil and the water sorption were calculated from the weight after incubation $\left(w_{i}\right)$ and the initial weight $\left(w_{0}\right)$ by

$$
\text { Sorption } \%=\frac{\left(w_{i}-w_{0}\right)}{w_{0}} \times 100 \% \text {. }
$$

The hydrolytic degradation was carried out at $37^{\circ} \mathrm{C}$ for 4 and 36 weeks, using phosphate buffer solution ( $\mathrm{PBS}, \mathrm{pH}=7.41$ ), containing $\mathrm{NaN}_{3}$ as bacteriostatic agent [18].

The enzymatic degradation was carried out by immersion of each specimen in a capped bottle containing $10 \mathrm{~mL}$ phosphate buffer solution ( $\mathrm{pH} 7.4$ ) with the porcine pancreatic lipase or porcine pancreatic trypsin concentration of $1 \mathrm{mg} / \mathrm{mL}$, at $37^{\circ} \mathrm{C}$ for 2 weeks. Degradation media were changed every day to ensure enzyme activity $[3,19,20]$.

The polyurethanes and their blends were cut before measurements into samples with an area about $1 \mathrm{~cm}^{2}$, dried to a constant weight at $50^{\circ} \mathrm{C}$ in vacuum drier, and weighed using an analytical balance. Next, they were immersed in containers and covered with appropriate solution using $10 \mathrm{~mL}$ per square of polymer sample and incubated in heating chamber in $37 \pm$ $1{ }^{\circ} \mathrm{C}$.

The changes of samples mass, their molecular weight, and surface structure were examined after incubation in mentioned solutions. Changes of samples mass and their molecular weights were calculated by (1). The presented values of experimental weight changes were the arithmetic mean of 3 measurements.

Size Exclusion Chromatography (SEC) was used to determine the weight-average $\left(M_{w}\right)$, number-average $\left(M_{n}\right)$ molecular weights, and the polydispersity $\left(M_{w} / M_{n}\right)$ of polyurethanes and their blends. Waters Alliance systems calibrated by polystyrene standards were used. THF with $1 \mathrm{v} / \mathrm{v}-\%$ acetic acid was used as eluent at a flow rate of $1.0 \mathrm{~mL} \cdot \mathrm{min}^{-1}$.

Microscopic observation of polymer surface was performed in reflected light with an optical microscope Nikon Alphaphot-2YS2 connected with digital photo camera Casio QY2900UX, at magnification 1:300.

\section{Results and Discussion}

Two polyesterurethanes and two polyether-esterurethanes were obtained and each of them was next blended with PLA. Composition of PURs and their blends is presented in Table 1.

Results of sunflower oil sorption by polyurethanes and their PLA blends are presented in Table 2.

Polyurethanes containing PTMG in soft segments absorbed much more oil than PURs with PCL. The mass of polyesterurethanes samples based on PCL and R,S-PHB increased only for about $1 \%$ independently on R,S-PHB amount in structure or on blending with PLA.

On the contrary polyether-esterurethanes (PUR 10 PHB+90PTMG and PUR $_{20 \text { PHB+80PTMG }}$ ) increased
TABLE 1: Composition of polyurethanes and their blends.

\begin{tabular}{lll}
\hline Sample & $\begin{array}{l}\text { Substrates used for soft } \\
\text { segments synthesis }\end{array}$ & PLA [wt\%] \\
\hline PUR $_{10 \mathrm{PHB}+90 \mathrm{PTMG}}$ & 10\%R,S-PHB + 90\%PTMG & 0 \\
PUR $_{10 \mathrm{PHB}+90 \mathrm{PTMG}} / \mathrm{PLA}$ & & 5 \\
PUR $_{20 \mathrm{PHB}+80 \mathrm{PTMG}}$ & 20\%R,S-PHB + 80\%PTMG & 0 \\
$\mathrm{PUR}_{20 \mathrm{PHB}+80 \mathrm{PTMG}} / \mathrm{PLA}$ & & 5 \\
\hline $\mathrm{PUR}_{10 \mathrm{PHB}+90 \mathrm{PCL}}$ & $10 \% \mathrm{R}, \mathrm{S}-\mathrm{PHB}+90 \% \mathrm{PCL}$ & 0 \\
$\mathrm{PUR}_{10 \mathrm{PHB}+90 \mathrm{PCL}} / \mathrm{PLA}$ & & 5 \\
$\mathrm{PUR}_{20 \mathrm{PHB}+80 \mathrm{PCL}}$ & $20 \% \mathrm{R}, \mathrm{S}-\mathrm{PHB}+80 \% \mathrm{PCL}$ & 0 \\
$\mathrm{PUR}_{20 \mathrm{PHB}+80 \mathrm{PCL}} / \mathrm{PLA}$ & & 5 \\
\hline
\end{tabular}

TABLE 2: The oil sorption by polyurethanes and their blends.

\begin{tabular}{lc}
\hline Sample & $\begin{array}{c}\text { The samples mass changes }( \pm \mathrm{SD}) \\
{[\mathrm{wt} \%]}\end{array}$ \\
\hline $\mathrm{PUR}_{10 \mathrm{PHB}+90 \mathrm{PTMG}}$ & $9.7 \pm 0.6$ \\
$\mathrm{PUR}_{10 \mathrm{PHB}+90 \mathrm{PTMG}} / \mathrm{PLA}$ & $26.1 \pm 1.9$ \\
$\mathrm{PUR}_{20 \mathrm{PHB}+80 \mathrm{PTMG}}$ & $8.2 \pm 0.4$ \\
$\mathrm{PUR}_{20 \mathrm{PHB}+80 \mathrm{PTMG}} / \mathrm{PLA}$ & $13.3 \pm 2.1$ \\
\hline $\mathrm{PUR}_{10 \mathrm{PHB}+90 \mathrm{PCL}}$ & $0.7 \pm 0.1$ \\
$\mathrm{PUR}_{10 \mathrm{PHB}+90 \mathrm{PCL}} / \mathrm{PLA}$ & $0.8 \pm 0.3$ \\
$\mathrm{PUR}_{20 \mathrm{PHB}+80 \mathrm{PCL}}$ & $1.4 \pm 0.5$ \\
$\mathrm{PUR}_{20 \mathrm{PHB}+80 \mathrm{PCL}} / \mathrm{PLA}$ & $1.1 \pm 0.2$ \\
\hline
\end{tabular}

their mass for 9.7 and $8.2 \%$, respectively, after incubation in lipid medium and this change was more pronounced for PUR with lower amount of R,S-PHB. It was observed previously (for similar polyurethanes) that introduction of R,S-PHB into the structure of polyurethanes based on PTMG accelerated the hydrogen bonds creation [21]. In that case the diffusion of lipid compounds into polymer network was difficult so the presence of higher amount of R,S-PHB in soft segments caused the reduction of oil sorption.

Blending of polyurethanes with PLA significantly enlarged the amount of absorbed oil. Even for the blends containing only $5 \%$ of PLA in total mass the arrangement of polyurethanes structure was disturbed and therefore the distance between polymer backbones was larger in comparison to the reference sample.

Polyurethanes based on PTMG absorbed more water than polyesterurethanes (see Figures 1 and 2). The presence of hydrophobic PCL in polyesterurethanes structure was probably the main reason of this. Also crystallinity of polyesterurethanes based on PCL (value of $\Delta \mathrm{H}$ of PUR $_{20 \mathrm{PHB}+80 \mathrm{PCL}}$ soft segments was $48.9 \mathrm{~J} / \mathrm{g}$ ) was higher than polyether-esterurethanes with PTMG (value of $\Delta \mathrm{H}$ of PUR $_{20 \mathrm{PHB}+80 \mathrm{PTMG}}$ soft segments was $18.5 \mathrm{~J} / \mathrm{g}$ ).

As mentioned earlier [21], introducing more R,S-PHB to PTMG soft segments caused the creation of more hydrogen bonds what made medium molecules penetration difficult. It was the reason of lower oil (Table 2) and water (Figure 1) sorption by polyether-esterurethanes with $20 \mathrm{wt} \%$ of R,S$\mathrm{PHB}$ in soft segment structure than by $\mathrm{PUR}_{10 \mathrm{PHB}+90 \mathrm{PTMG}}$. 
TABle 3: The mass changes of PURs and their blends with PLA after incubation in buffer and enzymes solutions.

\begin{tabular}{|c|c|c|c|c|}
\hline \multirow{3}{*}{ Sample } & \multicolumn{4}{|c|}{ The samples mass changes $( \pm \mathrm{SD})[\%]$} \\
\hline & \multicolumn{2}{|c|}{ Incubation in PBS } & \multirow{2}{*}{ Incubation in trypsin } & \multirow{2}{*}{ Incubation in lipase } \\
\hline & 4 weeks & 36 weeks & & \\
\hline PUR $_{10 \mathrm{PHB}+90 \mathrm{PTMG}}$ & $+1.3 \pm 0.6$ & $-3.3 \pm 1.6$ & $-0.3 \pm 0.1$ & $0.0 \pm 0.0$ \\
\hline $\mathrm{PUR}_{10 \mathrm{PHB}+90 \mathrm{PTMG}} / \mathrm{PLA}$ & $+2.6 \pm 0.4$ & $-2.1 \pm 0.4$ & $-0.3 \pm 0.1$ & $+0.3 \pm 0.1$ \\
\hline $\mathrm{PUR}_{20 \mathrm{PHB}+80 \mathrm{PTMG}}$ & $-0.5 \pm 0.4$ & $-1.5 \pm 0.4$ & $+0.9 \pm 0.1$ & $+1.9 \pm 0.0$ \\
\hline $\mathrm{PUR}_{20 \mathrm{PHB}+80 \mathrm{PTMG}} / \mathrm{PLA}$ & $-1.8 \pm 0.3$ & $-5.7 \pm 1.2$ & $-0.8 \pm 0.1$ & $+0.7 \pm 0.1$ \\
\hline $\mathrm{PUR}_{10 \mathrm{PHB}+90 \mathrm{PCL}}$ & $-0.2 \pm 0.1$ & $+3.1 \pm 0.1$ & $-0.4 \pm 0.1$ & $-0.5 \pm 0.3$ \\
\hline $\mathrm{PUR}_{10 \mathrm{PHB}+90 \mathrm{PCL}} / \mathrm{PLA}$ & $-3.7 \pm 1.8$ & $-4.5 \pm 1.5$ & $-0.6 \pm 0.1$ & $-0.5 \pm 0.5$ \\
\hline $\mathrm{PUR}_{20 \mathrm{PHB}+80 \mathrm{PCL}}$ & $+0.8 \pm 0.1$ & $-0.4 \pm 0.4$ & $-0.1 \pm 0.1$ & $+0.1 \pm 0.1$ \\
\hline $\mathrm{PUR}_{20 \mathrm{PHB}+80 \mathrm{PCL}} / \mathrm{PLA}$ & $-0.2 \pm 0.0$ & $-4.5 \pm 0.5$ & $-0.4 \pm 0.0$ & $+0.2 \pm 0.1$ \\
\hline
\end{tabular}

TABLE 4: Molecular weights of polyurethane $\left(\mathrm{PUR}_{10 \mathrm{PHB}+90 \mathrm{PTMG}}\right)$ and its blend ( $\left.\mathrm{PUR}_{10 \mathrm{PHB}+90 \mathrm{PTMG}} / \mathrm{PLA}\right)$ before and after incubation in PBS (4 weeks), lipase (L), and trypsin (T) (2 weeks).

\begin{tabular}{lccccc}
\hline Sample & $M_{n}$ & $M_{w}$ & $M_{w} / M_{n}$ & $\Delta M_{n}$ after incubation [\%] & $\Delta M_{w}$ after incubation [\%] \\
\hline PUR $_{10 \text { PHB+90PTMG }}$ & 38920 & 81030 & 2.1 & - & - \\
PUR $_{10 \text { PHB+90PTMG }}$ PBS & 32670 & 69920 & 2.1 & -16.0 & -13.7 \\
PUR $_{10 \text { PHB+90PTMG }}$ L & 35510 & 71020 & 2.0 & -8.8 & -12.4 \\
PUR $_{10 \text { PHB+90PTMG }}$ T & 27930 & 82670 & 3.0 & -28.2 & +2.0 \\
PUR $_{10 \text { PHB+90PTMG }}$ /PLA & 24280 & 82680 & 3.4 & -20.8 & - \\
PUR $_{10 \text { PHB+90PTMG }}$ /PLA PBS & 19230 & 41710 & 2.2 & -24.0 & -49.6 \\
PUR $_{10 \text { PHB+90PTMG }}$ /PLA L & 18440 & 55790 & 3.0 & -25.3 & -32.5 \\
PUR $_{10 \text { PHB+90PTMG }}$ /PLA T & 18150 & 63430 & 3.5 & & -23.3 \\
\hline
\end{tabular}

Blending of polyurethanes with PLA caused slight increase of the amount of absorbed water (see Figures 1 and 2 ). It was supposed that density of blends and the ordering of chains in polymer network had to be lower than pure polyurethanes what caused the easy migration of molecules of any medium into their structure.

The polyurethane chains can migrate from bulk to surface under the influence of incubation medium. In case when density of polymer is low the chains can easily migrate and their hydrophilic parts are collected on surface in aqueous media. After immersion of polyurethane in lipid environment its surface becomes enriched in hydrophobic groups [22].

The mass changes of polyurethanes and their blends with PLA after incubation in phosphate buffer and in enzymes solutions are presented in Table 3.

The samples mass of polyurethanes were almost not changed after incubation in used degradative solutions. Only a little mass reduction of samples was observed after 36 weeks of incubation in PBS, except for samples mass of $\mathrm{PUR}_{10 \mathrm{PHB}+90 \mathrm{PCL}}$ which even increased for $3.1 \%$. Previously it was demonstrated [21] that the decrease of molecular weight of polyurethanes based on PCL and $\mathrm{R}, \mathrm{S}$-PHB after hydrolysis in phosphate buffer took place whereas only small mass loss of polymer samples was noticed. Chains were cut but created short chains were not moved from polymer network so the sample mass was unchanged.

Blending of PURs with PLA caused the samples mass to be reduced about $4.5 \%$ after 36 weeks of incubation in PBS.
It seems that the term of two weeks of incubation in enzymatic media was too short for reduction of samples mass of polyurethanes and their blends.

The molecular weights of polymers and their percent change $(\Delta M)$ are presented in Tables 4-7.

The comparison of molecular weights of polyetheresterurethanes and their blends with PLA before and after incubation in all solutions indicated the hydrolytic degradation of polymer chains. Polymers containing more a-PHB in soft segments $\left(\mathrm{PUR}_{20 \mathrm{PHB}+80 \mathrm{PTMG}}\right.$ and $\mathrm{PUR}_{20 \mathrm{PHB}+80 \mathrm{PTMG}}$ / PLA) degraded faster than PUR $_{10 \mathrm{PHB}+90 \mathrm{PTMG}}$ and PUR $_{10 \mathrm{PHB}+90 \mathrm{PTMG}} / \mathrm{PLA}$.

Presence of enzymes influenced more efficiently the number-average molecular weight of $\mathrm{PUR}_{10 \mathrm{PHB}+90 \mathrm{PTMG}}$ and PUR $_{20 \mathrm{PHB}+80 \mathrm{PTMG}}$ than only hydrolytic conditions of buffer, despite the fact that time of their incubation in enzyme solutions was two times lower (2 weeks) than in PBS (4 weeks) (see Tables 4 and 5), except for the case when the PUR $_{10 \mathrm{PHB}+90 \mathrm{PTMG}}$ incubated in lipase solution. The soft segments of this polyurethane were built mainly with polyether and only $10 \%$ of PTMG was replaced by R,S-PHB with ester cleavages so the hydrolysis was hampered.

The tendency in differences of percentage change of the molecular weight in case of PUR/PLA blends (incubated in buffer and enzymatic solutions) was not such clear.

The changes of molecular weights of polyesterurethanes $\left(\right.$ PUR $_{10 \mathrm{PHB}+90 \mathrm{PCL}}$ and $\left.\mathrm{PUR}_{20 \mathrm{PHB}+80 \mathrm{PCL}}\right)$ and their blends with PLA indicated that they were degraded via chemical hydrolysis. The molecular weight of polymers incubated in enzyme 
TABLE 5: Molecular weights of polyurethane $\left(\mathrm{PUR}_{20 \mathrm{PHB}+80 \mathrm{PTMG}}\right)$ and its blend ( $\left.\mathrm{PUR}_{20 \mathrm{PHB}+80 \mathrm{PTMG}} / \mathrm{PLA}\right)$ before and after incubation in PBS (4 weeks), lipase (L), and trypsin (T) (2 weeks).

\begin{tabular}{lccccc}
\hline Sample & $M_{n}$ & $M_{w}$ & $M_{w} / M_{n}$ & $\Delta M_{n}$ after incubation [\%] & $\Delta M_{w}$ after incubation [\%] \\
\hline PUR $_{20 \text { PHB+80PTMG }}$ & 31350 & 107070 & 3.4 & - & - \\
PUR $_{20 \text { PHB+80PTMG }}$ PBS & 22830 & 55710 & 2.4 & -27.2 & -48.0 \\
PUR $_{20 \text { PHB+80PTMG }}$ L & 14510 & 49360 & 3.4 & -53.7 & -53.9 \\
PUR $_{20 \text { PHB+80PTMG }}$ T & 17400 & 52370 & 3.0 & -44.5 & -51.1 \\
\hline PUR $_{20 \text { PHB+80PTMG }}$ /PLA & 28370 & 114450 & 4.0 & - & - \\
PUR $_{20 \text { PHB }+80 \text { PTMG }}$ /PLA PBS & 18580 & 47010 & 2.5 & -34.5 & -58.9 \\
PUR $_{20 \text { PHB+80PTMG }}$ /PLA L & 15730 & 62790 & 4.0 & -44.6 & -45.1 \\
PUR $_{20 \text { PHB }+80 \text { PTMG }}$ /PLA T & 22700 & 55960 & 2.5 & -20.0 & -51.1 \\
\hline
\end{tabular}

TABLE 6: Molecular weights of polyurethane $\left(\mathrm{PUR}_{10 \mathrm{PHB}+90 \mathrm{PCL}}\right)$ and its blend $\left(\mathrm{PUR}_{10 \mathrm{PHB}+90 \mathrm{PCL}} / \mathrm{PLA}\right)$ before and after incubation in PBS, lipase $(\mathrm{L})$, and trypsin $(\mathrm{T})$.

\begin{tabular}{lccccc}
\hline Sample & $M_{n}$ & $M_{w}$ & $M_{w} / M_{n}$ & $\Delta M_{n}$ after incubation [\%] & $\Delta M_{w}$ after incubation [\%] \\
\hline PUR $_{10 \mathrm{PHB}+90 \mathrm{PCL}}$ & 42680 & 102940 & 2.4 & - & - \\
PUR $_{10 \mathrm{PHB}+90 \mathrm{PCL}}$ PBS & 33020 & 64100 & 1.9 & -22.6 & -37.7 \\
PUR $_{10 \mathrm{PHB}+90 \mathrm{PCL}} \mathrm{L}$ & 39660 & 102340 & 2.6 & -7.1 & -0.6 \\
$\mathrm{PUR}_{10 \mathrm{PHB}+90 \mathrm{PCL}} \mathrm{T}$ & 36720 & 97840 & 2.7 & -14.0 & -5.0 \\
\hline $\mathrm{PUR}_{10 \mathrm{PHB}+90 \mathrm{PCL}} /$ PLA & 35820 & 92690 & 2.6 & - & - \\
$\mathrm{PUR}_{10 \mathrm{PHB}+90 \mathrm{PCL}} / \mathrm{PLA} \mathrm{PBS}$ & 28830 & 55460 & 1.9 & -0.9 & -40.2 \\
$\mathrm{PUR}_{10 \mathrm{PHB}+90 \mathrm{PCL}} / \mathrm{PLA} \mathrm{L}$ & 35510 & 87280 & 2.5 & -1.5 & -5.8 \\
$\mathrm{PUR}_{10 \mathrm{PHB}+90 \mathrm{PCL}} / \mathrm{PLA} \mathrm{T}$ & 35290 & 89910 & 2.6 & -3.0 & \\
\hline
\end{tabular}

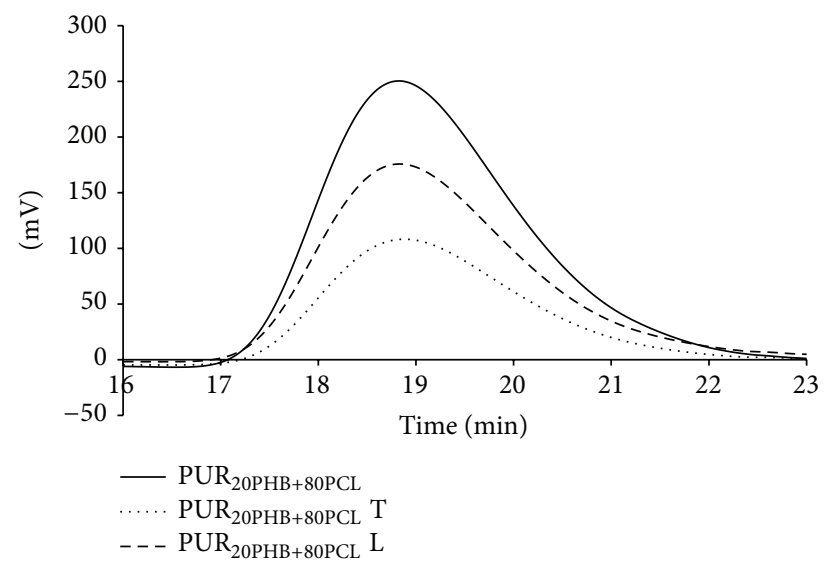

FigURE 3: SEC traces of PUR $20 \mathrm{PHB}+80 \mathrm{PCL}$ before $\left(\mathrm{PUR}_{20 \mathrm{PHB}+80 \mathrm{PCL}}\right)$ and after incubation in trypsin $\left(\mathrm{PUR}_{20 \mathrm{PHB}+80 \mathrm{PCL}} \mathrm{T}\right)$ and in lipase $\left(\mathrm{PUR}_{20 \mathrm{PHB}+80 \mathrm{PCL}} \mathrm{L}\right)$.

solutions was not such reduced like in case of PBS incubation (see Tables 6 and 7). The presence of enzymes in solution blocked the chemical hydrolysis of ester groups.

$M_{n}$ of polyurethane $\mathrm{PUR}_{20 \mathrm{PHB}+80 \mathrm{PCL}}$ after incubation in PBS and trypsin was only slightly higher than before (Table 7). Simultaneously the polydispersity and $M_{w}$ were decreased but the sample masses (Table 3) after incubation in mentioned solutions were almost not changed. It suggested the structural changes of polymer network induced by degradative solutions. The shape of SEC traces of $\mathrm{PUR}_{20 \mathrm{PHB}+80 \mathrm{PCL}}$ was similar before and after incubation in enzymes (Figure 3 ). Blending of polyurethane with PLA

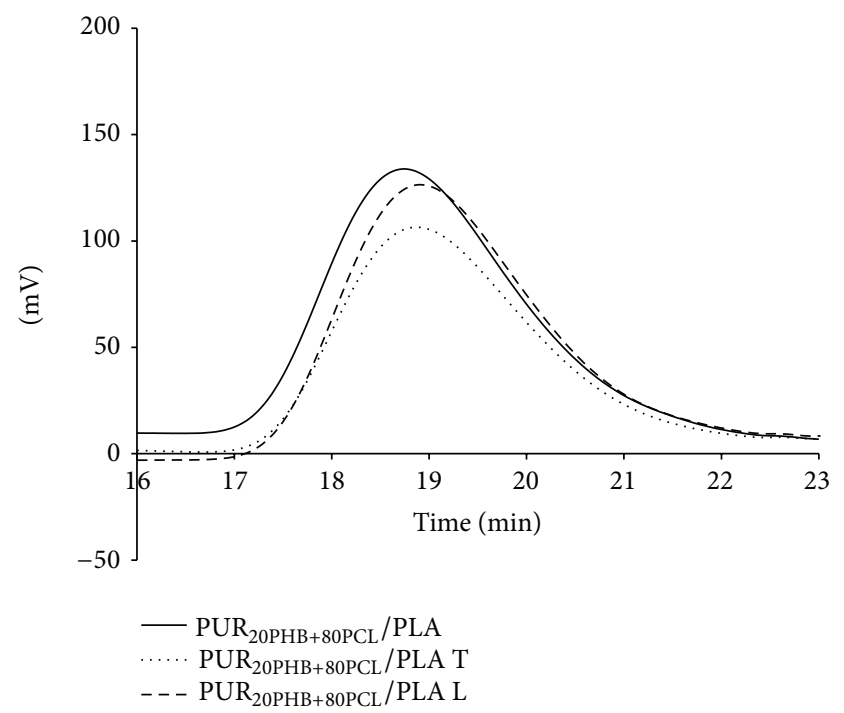

FIGURE 4: SEC traces of PUR $20 \mathrm{PHB}+80 \mathrm{PCL} / \mathrm{PLA}$ before $\left(\mathrm{PUR}_{20 \mathrm{PHB}+80 \mathrm{PCL}} /\right.$ $\mathrm{PLA})$ and after incubation in trypsin $\left(\mathrm{PUR}_{20 \mathrm{PHB}+80 \mathrm{PCL}} / \mathrm{PLA} \mathrm{T}\right)$ and in lipase $\left(\mathrm{PUR}_{20 \mathrm{PHB}+80 \mathrm{PCL}} / \mathrm{PLA} \mathrm{L}\right)$.

caused that SEC traces shifted to lower molecular weight (Figure 4) what indicated that degradation had been started prior to SEC analysis of the materials.

The surface structure of polyurethanes and their blends after incubation in both enzymatic solutions are presented in Figures 5 and 6.

The reduction of molecular weight of investigated polymers and unchanged mass of sample after incubation in 
TABLE 7: Molecular weights of polyurethane $\left(\mathrm{PUR}_{20 \mathrm{PHB}+80 \mathrm{PCL}}\right)$ and its blend $\left(\mathrm{PUR}_{20 \mathrm{PHB}+80 \mathrm{PCL}} / \mathrm{PLA}\right)$ before and after incubation in PBS, lipase $(\mathrm{L})$, and trypsin $(\mathrm{T})$.

\begin{tabular}{|c|c|c|c|c|c|}
\hline Sample & $M_{n}$ & $M_{w}$ & $M_{w} / M_{n}$ & $\Delta M_{n}$ after incubation [\%] & $\Delta M_{w}$ after incubation [\%] \\
\hline $\mathrm{PUR}_{20 \mathrm{PHB}+80 \mathrm{PCL}}$ & 19240 & 51810 & 2.7 & - & - \\
\hline $\mathrm{PUR}_{20 \mathrm{PHB}+80 \mathrm{PCL}} \mathrm{PBS}$ & 19440 & 34230 & 1.8 & +1.0 & -33.9 \\
\hline $\mathrm{PUR}_{20 \mathrm{PHB}+80 \mathrm{PCL}} \mathrm{L}$ & 15940 & 51130 & 3.2 & -17.1 & -1.3 \\
\hline $\mathrm{PUR}_{20 \mathrm{PHB}+80 \mathrm{PCL}} \mathrm{T}$ & 21010 & 50020 & 2.4 & +9.2 & -3.5 \\
\hline $\mathrm{PUR}_{20 \mathrm{PHB}+80 \mathrm{PCL}} / \mathrm{PLA}$ & 23160 & 56580 & 2.4 & - & - \\
\hline $\mathrm{PUR}_{20 \mathrm{PHB}+80 \mathrm{PCL}} / \mathrm{PLA} \mathrm{PBS}$ & 17090 & 32690 & 1.9 & -26.2 & -42.2 \\
\hline $\mathrm{PUR}_{20 \mathrm{PHB}+80 \mathrm{PCL}} / \mathrm{PLA} \mathrm{L}$ & 21380 & 48980 & 2.3 & -7.7 & -13.4 \\
\hline $\mathrm{PUR}_{20 \mathrm{PHB}+80 \mathrm{PCL}} / \mathrm{PLA} \mathrm{T}$ & 20330 & 49720 & 2.5 & -12.2 & -12.1 \\
\hline
\end{tabular}

Sample
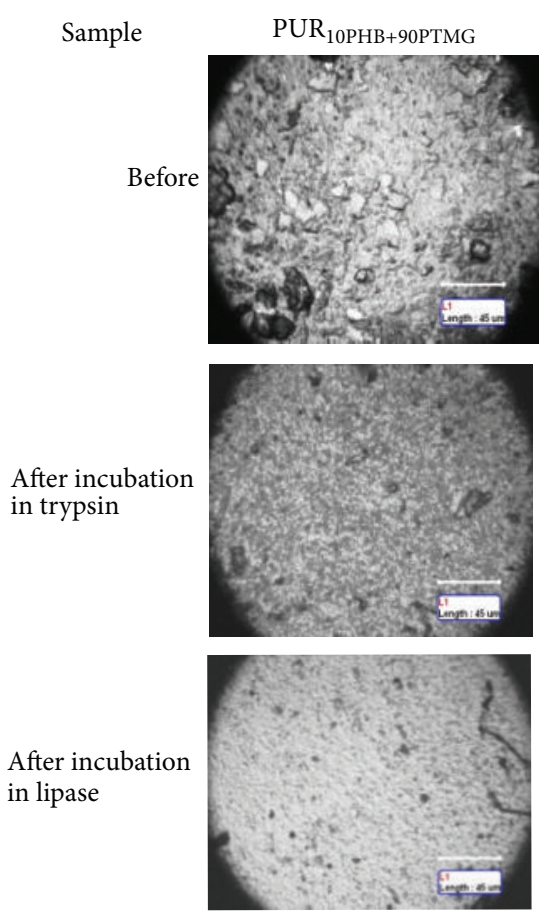

$\mathrm{PUR}_{10 \mathrm{PHB}+90 \mathrm{PTMG}} / \mathrm{PLA}$
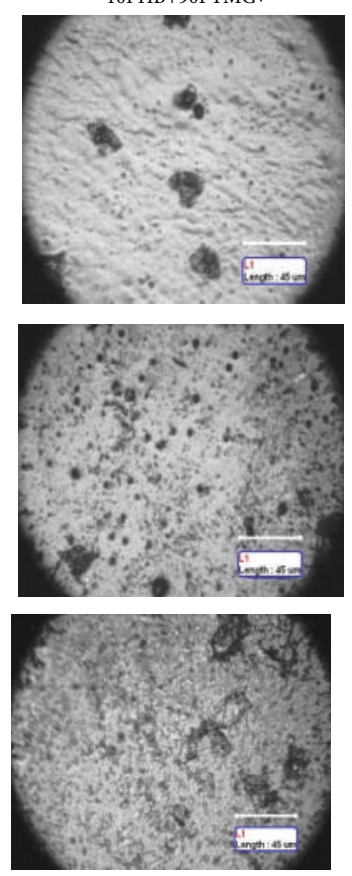

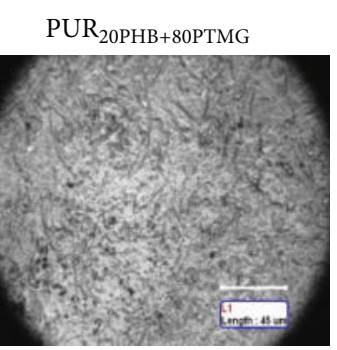

$\mathrm{PUR}_{20 \mathrm{PHB}+80 \mathrm{PTMG}} / \mathrm{PLA}$
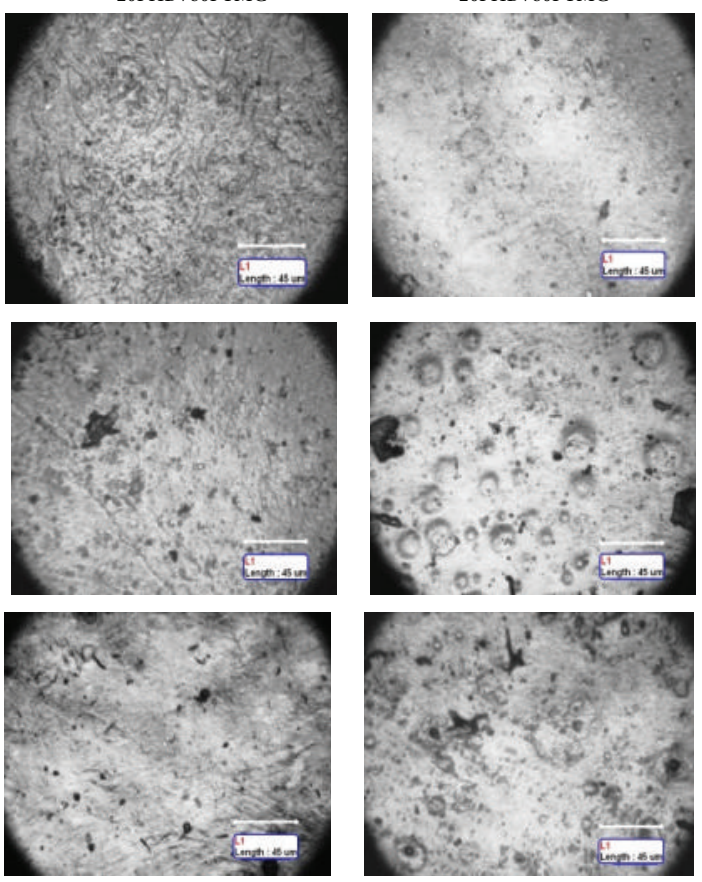

FIGURE 5: The surface structure of polyether-esterurethanes and their blends before and after incubation in enzyme solutions.

degradative media suggested that polymers degraded due to chemical hydrolysis.

But the surface structure of polyurethanes and their blends (Figures 5 and 6) after incubation in both enzymatic solutions indicated enzymatic degradation, which started despite the lack of mass lost (Table 3). It is known that large enzymes cannot penetrate into the polymer network and enzymatic degradation is observed by the surface erosion [6]. In some cases the surface of investigated became more smooth (like for $\mathrm{PUR}_{10 \mathrm{PHB}+90 \mathrm{PCL}} / \mathrm{PLA}$ incubated in lipase) or the erosion was clearly visible $\left(\mathrm{PUR}_{20 \mathrm{PHB}+80 \mathrm{PCL}}\right.$ or $\mathrm{PUR}_{10 \mathrm{PHB}+90 \mathrm{PCL}} / \mathrm{PLA}$ incubated in trypsin solution) (Figure 6). The surface erosion is more pronounced in case of polyesterurethanes and their blends (Figure 6) than polyether-esterurethanes (Figure 5).

Despite the fact that sample mass reduction was not yet observed after 2 weeks of incubation in enzyme solution the much lower reduction of molecular weight and the surface erosion of PURs with PCL suggested that their enzymatic degradation has been started. Polyesterurethanes PUR $_{10 \mathrm{PHB}+90 \mathrm{PCL}}$ and $\mathrm{PUR}_{20 \mathrm{PHB}+80 \mathrm{PCL}}$ and their blends seemed to be more sensitive to the enzymatic degradation than PURs based on PTMG.

\section{Conclusion}

The presence of poly $([\mathrm{D}, \mathrm{L}]$-lactide $)$ in polyurethane blends accelerated their degradation in hydrolytic and enzymatic solutions. The significant reduction of molecular weight of polymer samples after incubation in phosphate buffer and the lack of samples mass changes after incubation in enzymes solutions suggested that polyurethanes and their blends were degraded via chemical hydrolysis. The investigations of morphology of the surface structure which was changed after the incubation in both enzymes indicated that the enzymatic hydrolysis has been already initiated. Obtained polyurethanes 


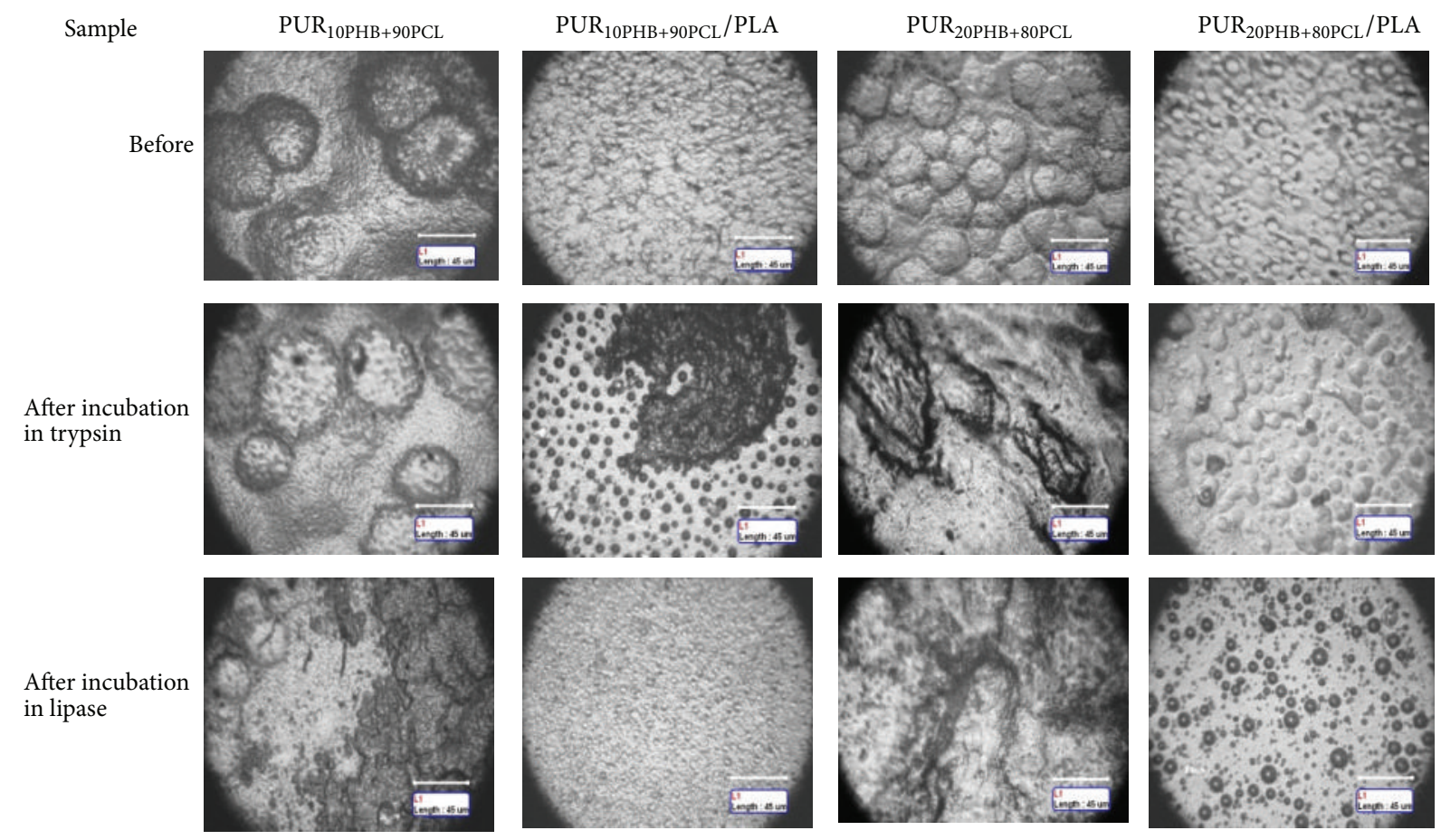

FiguRE 6: The surface structure of polyesterurethanes and their blends before and after incubation in enzyme solutions.

and their blends with poly([D,L]-lactide) could be useful for long-term degradative material for tissue engineering.

\section{Conflict of Interests}

The authors declare that there is no conflict of interests regarding the publication of this paper.

\section{References}

[1] P. Jurkowski, Habilitation Thesis, Ludwik Rydygier Collegium Medicum, Bydgoszcz, Poland, 2001.

[2] H. S. Azevedo and R. L. Reis, "Understanding the enzymatic degradation of biodegradable polymers and strategies to control their degradation rate," in Biodegradable Systems in Tissue Engineering and Regenerative Medicine, R. L. Reis and J. San Román, Eds., p. 186, CRC Press, New York, NY, USA, 2005.

[3] H. Peng, J. Ling, J. Liu, N. Zhu, X. Ni, and Z. Shen, "Controlled enzymatic degradation of poly( $\varepsilon$-caprolactone)-based copolymers in the presence of porcine pancreatic lipase," Polymer Degradation and Stability, vol. 95, no. 4, pp. 643-650, 2010.

[4] H. Lin Xi, Y. Peck, X. W. Wang, and D. A. Wang, "Surface patterning and modification of polyurethane biomaterials using silsesquioxane-gelatin additives for improved endothelial affinity," Science China Chemistry, vol. 57, no. 4, pp. 596-604, 2014.

[5] M. Mândru, C. Ciobanu, S. Vlad, M. Butnaru, L. Lebrun, and M. Popa, "Characteristics of polyurethane-based sustained release membranes for drug delivery," Central European Journal of Chemistry, vol. 11, no. 4, pp. 542-553, 2013.

[6] L. H. Chan-Chan, C. Tkaczyk, R. F. Vargas-Coronado, J. M. Cervantes-Uc, M. Tabrizian, and J. V. Cauich-Rodriguez, "Characterization and biocompatibility studies of new degradable poly(urea)urethanes prepared with arginine, glycine or aspartic acid as chain extenders," Journal of Materials Science: Materials in Medicine, vol. 24, no. 7, pp. 1733-1744, 2013.

[7] E. Kon, G. Filardo, S. Zaffagnini et al., "Biodegradable polyurethane meniscal scaffold for isolated partial lesions or as combined procedure for knees with multiple comorbidities: clinical results at 2 years," Knee Surgery, Sports Traumatology, Arthroscopy, vol. 22, no. 1, pp. 128-134, 2014.

[8] E. Ozsagiroglu, B. Iyisan, and Y. A. Guvenilir, "Biodegradation and characterization studies of different kinds of polyurethanes with several enzyme solutions," Polish Journal of Environmental Studies, vol. 21, no. 6, pp. 1777-1782, 2012.

[9] R. T. H. Chan, C. J. Garvey, H. Marcal, R. A. Russell, P. J. Holden, and L. J. R. Foster, "Manipulation of polyhydroxybutyrate properties through blending with ethyl-cellulose for a composite biomaterial," International Journal of Polymer Science, vol. 2011, Article ID 651549, 8 pages, 2011.

[10] Q. Liu, H. Zhang, B. Deng, and X. Zhao, "Poly(3-hydroxybutyrate) and poly(3-hydroxybutyrate-co-3-hydroxyvalerate): structure, property, and fiber," International Journal of Polymer Science, vol. 2014, Article ID 374368, 11 pages, 2014.

[11] V. Piddubnyak, P. Kurcok, A. Matuszowicz et al., "Oligo3-hydroxybutyrates as potential carriers for drug delivery," Biomaterials, vol. 25, no. 22, pp. 5271-5279, 2004.

[12] A. Marcos-Fernández, G. A. Abraham, J. L. Valentin, and J. San Román, "Synthesis and characterization of biodegradable nontoxic poly(ester-urethane-urea)s based on poly( $\varepsilon$-caprolactone) and amino acid derivatives," Polymer, vol. 47, pp. 785-798, 2006.

[13] M. A. Woodruff and D. W. Hutmacher, "The return of a forgotten polymer-polycaprolactone in the 21st century," Progress in Polymer Science, vol. 35, no. 10, pp. 1217-1256, 2010.

[14] J. Brzeska, A. Heimowska, H. Janeczek, M. Kowalczuk, and M. Rutkowska, "Polyurethanes based on atactic poly $[(R, S)-3$ hydroxybutyrate]: preliminary degradation studies in simulated 
body fluids," Journal of Polymers and the Environment, vol. 22, no. 2, pp. 176-182, 2014.

[15] J. Brzeska, P. Dacko, H. Janik, M. Kowalczuk, and M. Rutkowska, "Biodegradowalne poliuretany i sposób ich wytwarzania," PL Patent Number 212763, 2012.

[16] H. Arslan, G. Adamus, B. Hazer, and M. Kowalczuk, "Electrospray ionisation tandem mass spectrometry of poly $[(R, S)-3-$ hydroxybutanoic acid] telechelics containing primary hydroxy end groups," Rapid Communications in Mass Spectrometry, vol. 13, no. 24, pp. 2433-2438, 1999.

[17] A. Szelest-Lewandowska, A. Skupień, and B. Masiulanis, "Syntezy i właściwości nowych poliuretanów dla medycyny," Elastomery, vol. 6, no. 6, pp. 3-14, 2002 (Polish).

[18] M. Glarner and S. Gogolewski, "Degradation and calcification in vitro of new bioresorbable terpolymers of lactides with an improved degradation pattern," Polymer Degradation and Stability, vol. 92, no. 2, pp. 310-316, 2007.

[19] A. Kulkarni, J. Reiche, J. Hartmann, K. Kratz, and A. Lendlein, "Selective enzymatic degradation of poly( $\varepsilon$-caprolactone) containing multiblock copolymers," European Journal of Pharmaceutics and Biopharmaceutics, vol. 68, no. 1, pp. 46-56, 2008.

[20] C. Ferris, M. Violante De Paz, F. Zamora, and J. A. Galbis, "Dithiothreitol-based polyurethanes. Synthesis and degradation studies," Polymer Degradation and Stability, vol. 95, no. 9, pp. 1480-1487, 2010.

[21] J. Brzeska, Thesis Gdynia, Maritime University, 2010.

[22] P. Vermette, H. J. Griesser, G. Laroche, and R. Guidoin, Biomedical Applications of Polyurethanes, Eurekah, Charlotte, NC, USA, 2001. 

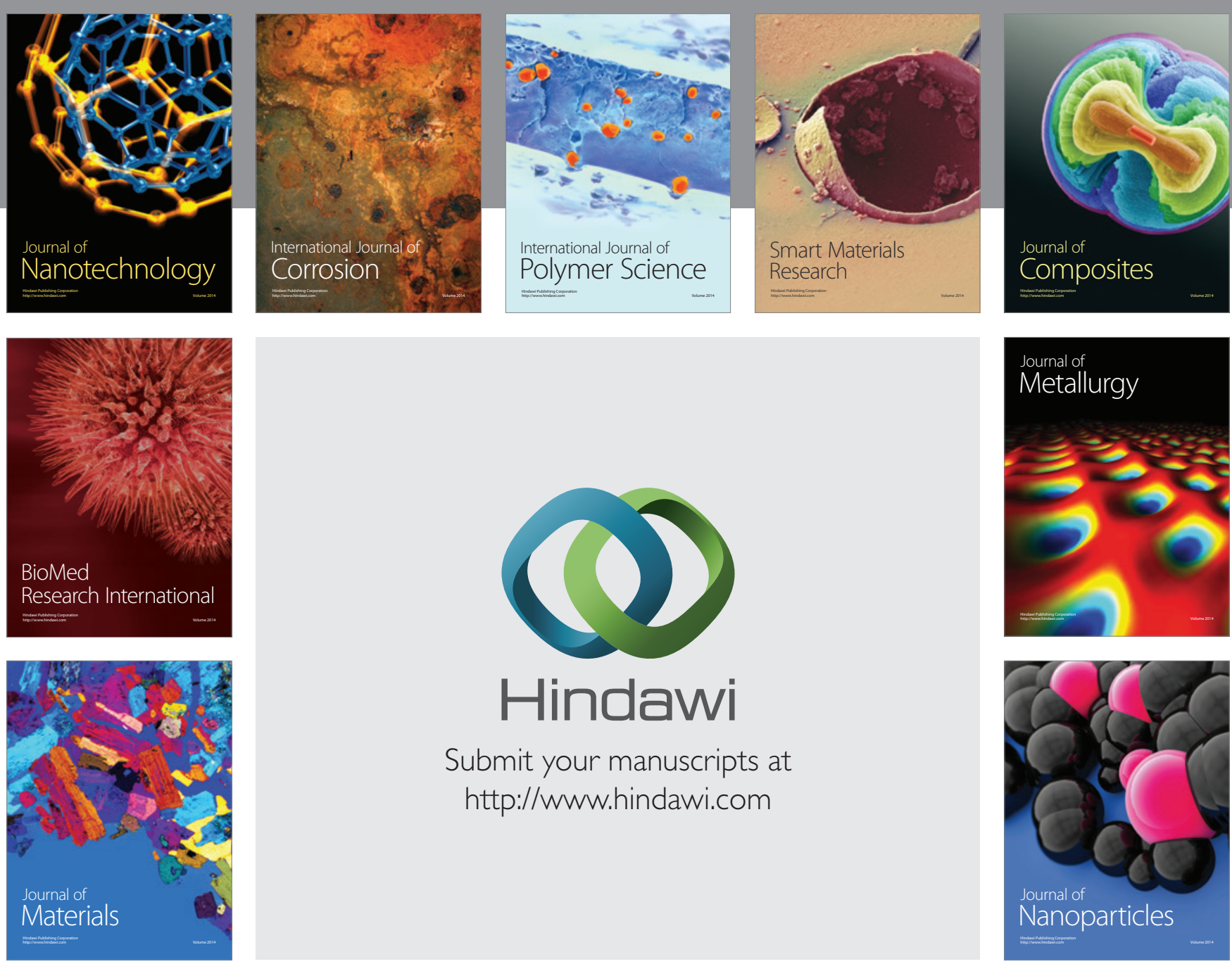

Submit your manuscripts at http://www.hindawi.com
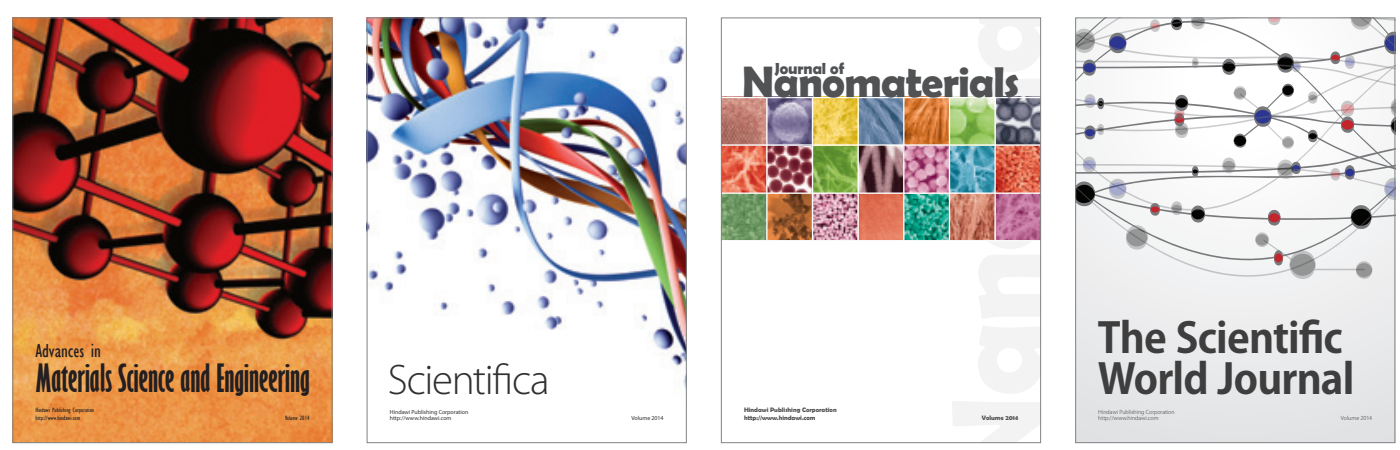

\section{The Scientific World Journal}
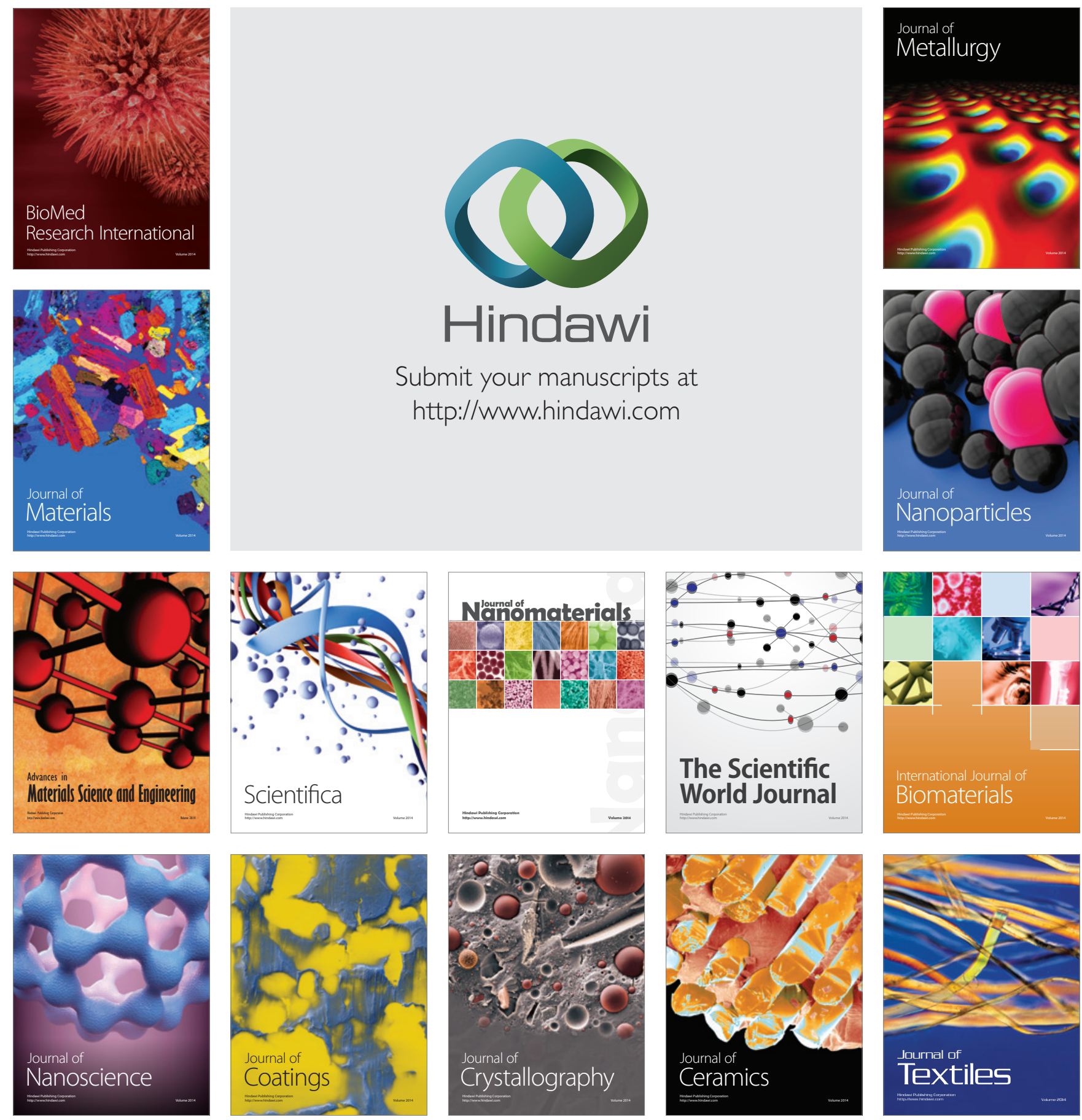